\title{
PEMODELAN SESAR PASCA GEMPA DENGAN INVERSI DATA GRAVITASI TIME LAPSE
}

\author{
Muhammad Zuhdi*, Muhammad Taufik, Sutrio, Syahrial Ayub \\ Program Studi Pendidikan Fisika, Universitas Mataram \\ Email: zuhdiunram@gmail.com
}

DOI: http://dx.doi.org/10.29303/jpft.v5i1.1174

\begin{abstract}
Time lapse or $4 D$ gravity is the development of gravity methods with the fourth dimension is time. This method is characterized by repetitive measurements over a period of time using a highprecision gravity measuring device (gravimeter) which is supported by high accuracy measurement of position. In the case of a fault that triggers an earthquake, layers that have a different density between layers will have the effect of changing the measured value of the gravitational field on the surface. The difference in the value of measured gravity before and after the occurrence of a fault as a result of an earthquake is what gives the value of time lapse gravity. The model of position displacement of the layers before and after the earthquake, provides a model of density between times whose gravitational anomalies can be calculated by forward response. The response of time-lapse forward model (synthetic data) is then optimized to obtain an inversion model. Inversion programming is made using the Mathlab program which is based on the semi-infinite horizontal slab equation. The model parameters that are optimized are horizontal position, depth, and amplitude factor of faulted layers. The program testing on 3 different synthetic data shows that the fastest optimization was obtained in the 7th iteration step. The smallest RMS error from the 3 models was 1.23. 10-5. This inversion program can be applied to time lapse gravity anomalies results of measurements in the field in active fault zones before and after the occurrence of an earthquake.
\end{abstract}

Keywords: Gravity, Inversion, Modeling , Time Lapse

\section{PENDAHULUAN}

Indonesia merupakan daerah yang sangat berpotensi untuk terjadinya gempa dengan skala besar maupun kecil. Gempa di Indonesia relatif sering terjadi karena berada pada ring of fire. Indonesia berada pada zona batas-batas lempeng tektonik yaitu lempeng Eurasia, lempeng Indo-Australia dan lempeng Pasifik. Bagian selatan Indonesia merupakan batas lempeng Indo-Australia yang menunjam pada Eurasia dan membentuk zona subduksi. Di Laut Banda juga terjadi penunjaman Lempeng Pasifik ke dalam Lempeng Eurasia. Batas Lempeng Pasifik dan Indo-Australia berupa collision zone membentuk pegunungan Jayawijaya. Batas-batas lempeng ini merupakan daerah dengan frekwensi kejadian gempa yang sangat tinggi.

Gambar 1 menunjukkan posisi Indonesia yang berada pada batas-batas lempeng tektonik yaitu Lempeng IndoAustralia (warna putih), Eurasia (warna krim) dan Lempeng Pasifik (warna abu-abu). Lempeng-lempeng ini selalu bergerak relatif satu terhadap yang lainnya sehingga pada batas-batasnya menimbulkan gesekan akibat tekanan dari tiap-tiap lempeng. Pelepasan energi saat gaya tektonik melebihi ambang batas gesekan inilah yang menimbulkan gempa dengan pelepasan energi potensial elastik yang ditransmisikan sebagai gelombang gempa. Hal yang melatarbelakangi penelitian ini adalah pentingya upaya mengetahui model, pososi dan mekanisme sesar sebagai dasar dalam mitigasi bencana geologi terutama bencana gempa. Metode gravitasi antar waktu (time lapse) merupakan pengembangan dari metode gravitasi dengan waktu sebagai demensi keempatnya. Prinsip metoda ini adalah pengukuran keseluruhan yang berulang secara periodik untuk mengetahui perubahan respon nilai gravitasi sebagai akibat perubahan rapat massa di bawah permukaan. 


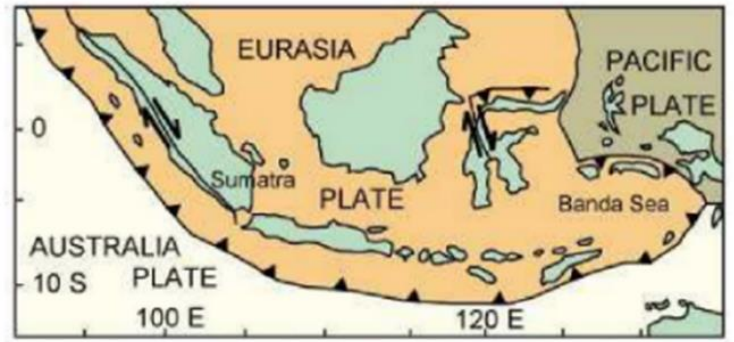

Gambar 1. Posisi Indonesia yang berada pada batas-batas lempeng tektonik

Gempa tektonik selalu terjadi pada zona sesar. Zona sesar ini merupakan zona patahan akibat tekanan lempeng tektonik melebihi ambang batas elastik material penyusun kerak bumi, sehingga perlapisan bumi menjadi patah atau yang dikenal dengan istilah sesar. Patahan ini menjadikan perlapisan batuan dengan densitas yang hampir seragam secara lateral menjadi terpisah secara vertikal. Patahan inilah yang memberikan nilai gravitasi yang berbeda antara sebelum dan sesudah terjadinya gempa sehingga memberikan anomaly gravitasi antar waktu (time lapse).

Untuk mengetahui perubahan struktur bawah permukaan sebelum dan sesudah terjadinya sesar akibat gempa, perlu dibuat pemodelan kedepan dari suatu sesar. Model ini akan menjadi dasar perhitungan secara forward untuk mendapatkan hasil berupa data sintetis.

Program Inversi untuk pemodelan sesar dibuat dengan parameter model yang realistis sebagaimana nilai parameter riil di lapangan. Program inversi ini kemudian diuji-coba menggunakan data sintetis sebagai hasil dari forward modelling.

Metoda gravitasi antar waktu (time lapse) telah banyak digunakan untuk identifikasi dan monitoring berubahan massa di bawah permukaan. Metode gaya berat mikro antar waktu digunakan untuk memonitor produksi gas di reservoir bawah laut dengan gravimeter berketelitian hingga 4 mikroGal. Tingkat kepercayaan hasil pengukuran berada pada angka $80 \%$ (Eiken, et al. 2004). Gettings et al. (2002), mengukur nilai gravitasi mikro antar waktu di sekitar sumber geothermal geysers untuk mendeteksi amblesan akibat perubahan massa selama masa produksi dengan laju amblesan $2 \pm 2$ mikroGal dan anomali antar waktu (time lapse) sebesar $10 \pm 8$ mikroGal. Anomali gravitasi antar waktu juga telah digunakan untuk memonitor laju injeksi air pada akuifer buatan artificial aquifer storage and recovery (ASR) di Leyden Colorado. Metoda ini terbukti sukses bahkan hingga dapat mendeteksi pergerakan air di dalam aquiver (Dafis \& Batzle 2008).

Metode pemodelan inversi gravitasi antar waktu telah dilakukan untuk identifikasi injeksi fluida pada reservoir (Zuhdi et al. 2018). Pemodelan inversi gravitasi time lapse untuk kasus sesar pasca gempa belum pernah dilakukan oleh peneliti sebelumnya.

Pemodelan maju dilakukan untuk mendapatkan data sintetis anomaly gravitasi 4D pasca gempa. Model ini di dapatkan dengan metode konvolusi gravitasi. Untuk mengetahui adanya bentuk persamaan konvolusi di dalam anomali gravitasi, diambil komponen vertikal gravitasi persamaan:

$$
\begin{aligned}
& \Delta g_{z}(x, y, z)= \\
& =-G \int_{0}^{\infty} \int_{-\infty}^{\infty} \int_{-\infty}^{\infty} \frac{\Delta \rho(\alpha, \beta, \gamma)(z-\gamma)}{\left\{(x-\alpha)^{2}+(y-\beta)^{2}+(z-\gamma)^{2}\right\}^{3 / 2}} d \alpha d \beta d \gamma \\
& \Delta g_{z}(x, y, z)= \\
& \int_{0}^{\infty} \int_{-\infty}^{\infty} \int_{-\infty}^{\infty} \Delta \rho(\alpha, \beta, \gamma) \cdot R_{z}(x-\alpha, y-\beta, z-\gamma) d \alpha d \beta d \gamma \\
& =\rho(\alpha, \beta, \gamma) * R_{z}(x, y, z)
\end{aligned}
$$

dengan $R z(x, y, z)$ adalah operator konvolusi., $(\alpha, \beta, \gamma)$ adalah koordinat elemen massa , $\mathrm{G}$ adalah konstanta umum gravitasi, $(x, y, z)$ adalah koordinat stasiun pengukuran dan $z$ adalah kedalaman (Kadir, 1999).

Dari persamaan 2 terlihat bahwa anomali gravitasi adalah hasil konvolusi antara distribusi rapat massa $\rho(\alpha, \beta, \gamma)$ dan 
operator konvolusi $R z(x, y, z)$. Operator ini berhubungan dengan bentuk dan kedalaman benda.

Pengukuran gravitasi dilakukan dengan alat ukur percepatan gravitasi yang disebut dengan gravimeter. Alat ini bekerja berdasarkan perubahan panjang pegas akibat perubahan nilai gravitasi. Sesuai hukum Hooke tentang pegas, perubahan panjang pegas berbanding lurus (linear) terhadap besarnya gaya tarik. Gravitasi yang terukur adalah nilai gravitasi relatif terhadap suatu titik yang diketahui nilai gravitasi mutlaknya yang disebut dengan titik ikat.

Hasil bacaan yang terukur oleh gravimeter, merupakan angka skala yang harus diubah dalam satuan mikrogal setelah melalui koreksi apungan (drift). Data kemudian dikoreksi dengan beberapa tahap untuk mendapatkan anomali Bouger. Perhitungan anomali gravitasi mikro antar waktu dilakukan dengan mengurangkan gravitasi observasi, anomali Bouguer sederhana ataupun anomali Bouguer lengkap, tergantung dari perubahan yang terjadi di daerah tersebut. Anomali Bouguer lengkap merupakan selisih antara nilai gravitasi pengamatan dengan gravitasi teoritik yang didefinisikan pada titik pengamatan bukan pada bidang referensi, baik ellipsoid maupun muka laut rata-rata.

\section{METODE PENELITIAN}

Tahap pertama penelitian ini adalah pembuatan model kedepan untuk mendapatkan data sintetis anomaly gravitasi antar waktu akibat sesar pasca gempa. Data sintetis dibuat dengan parameter fisis berdasarkan data real di lapangan. Data sintetis ini kemudian digunakan untuk uji coba program utama yaitu program inversi gravitasi antar waktu akibat sesar. Tahap selanjutnya adalah pembuatan program inversi gravitasi antar waktu akibat sesar pasca gempa yang memberikan gambaran beberapa perubahan parameter fisika akibat sesar pasca gempa.

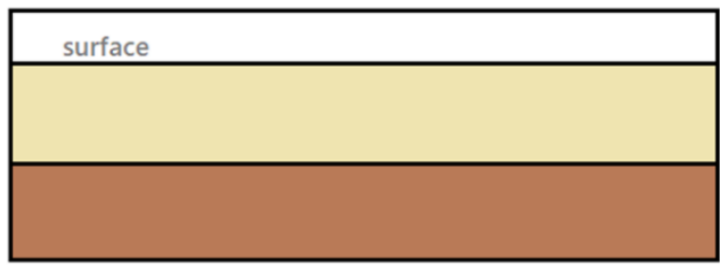

( a )

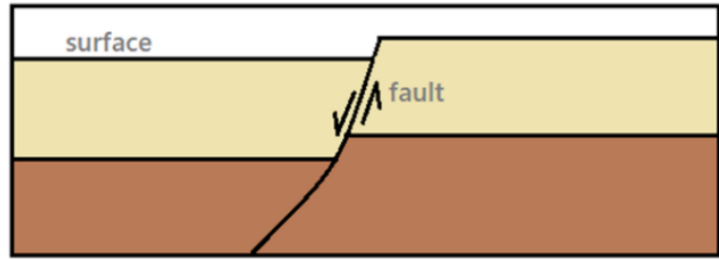

(b)

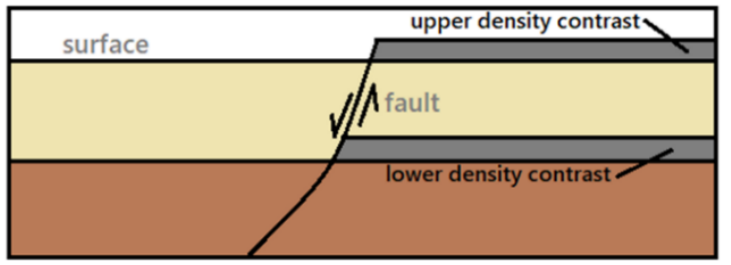

(c)

Gambar 2. (a) Posisi perlapisan sebelum terjadi-nya sesar, (b) Posisis perlapisan setelah terjadinya sesar, (c) Kontras densitas antar waktu akibat terjadinya sesar

Gambar 2a menunjukkan posisi perlapisan sebelum terjadinya sesar. Gambar 2b menunjukkan posisi perlapisan yang telah berubah setelah terjadinya sesar. Gambar 2c menunjukkan kontras densitas antar waktu akibat terjadinya sesar. Kontras densitas bagian atas pada gambar 2c berada pada posisi di permukaan, sehingga akan hilang dengan sendirinya pada saat terkoreksi bouger dan terrain, sehingga model densitas antar waktu hanya berasal dari kedalaman batas perlapisan saja.

Pemodelan forward dilakukan untuk mendapatkan data sintetis. Pemodelan forward dilakukan dengan metode konvolusi gravitasi menggunakan persamaan 2 .

Pemodelan inversi sesar pasca gempa yang dilakukan pada kasus ini diasumsikan merupakan anomali yang hanya berasal dari kedalaman batas kontras densitas rendah dan tinggi. Densitas tinggi berada pada kedalaman di bawah kedalaman densitas 
rendah (lapisan teratas). Inversi ini didasarkan pada model semi-infinite horizontal slab dengan ketebalan slab sesuai dengan disposisi sesar pada komponen vertikal. Hasil inversi ini diharapkan dapat menggambarkan bentuk geometri pergerseran sesar yang sesungguhnya, yang meliputi kontras densitas perlapisan dan pergeseran sesar kearah vertikal.

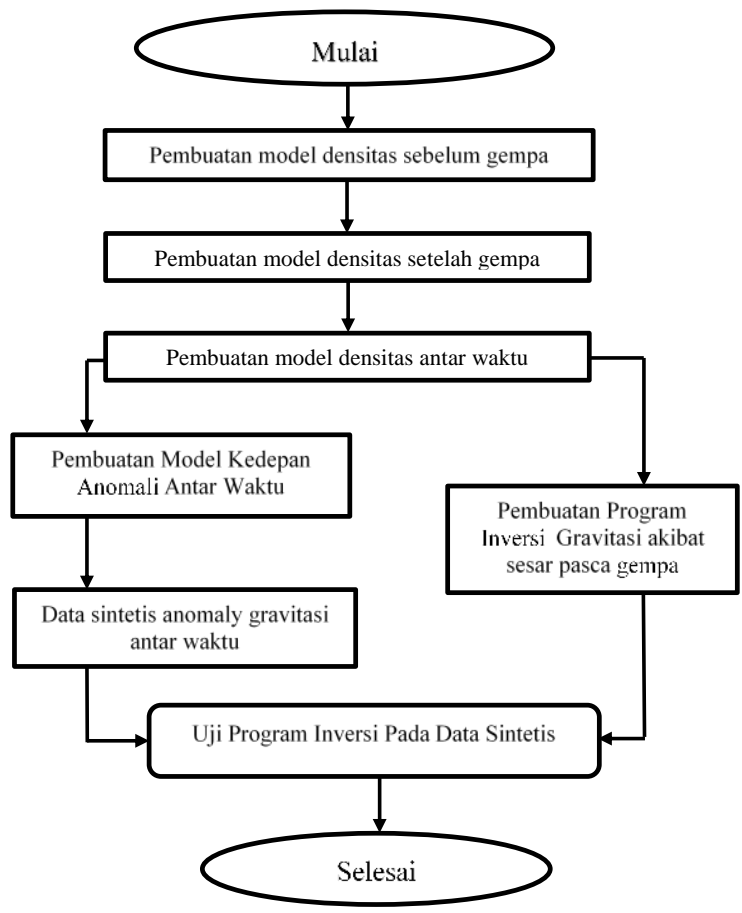

Gambar 3. Diagram Alir Penelitian

Gambar 3 menunjukkan diagram alir penelitian. Ujicoba Program Inversi dilakukan untuk 3 model sintetis dengan parameter yang berbeda. Formulasi anomali gravitasi untuk semi-infinite horizontal slab dirumuskan oleh Telford et al. (1990) dengan persamaan:

$$
g=4,07 \cdot 10^{-3} \sigma t\left\{\frac{\pi}{2}+\tan ^{-1}\left(\frac{x}{h}\right)\right\}
$$

Dengan $g$ adalah nilai gravitasi, $\sigma$ adalah kontras densitas antara slab dengan sekitarnya, $\mathrm{t}$ adalah ketebalan, $\mathrm{h}$ adalah kedalaman slab dan $\mathrm{x}$ adalah posisi sesar. Parameter model yang dioptimasi pada proses inversi pada program yang akan dibuat adalah densitas, kedalaman dan posisi sesar. Hasil perkalian antara $\sigma$ dan $t$ disebut dengan faktor amplitudo A, sehingga persamaan 3 menjadi:

$$
g=4,07 \cdot 10^{-3} A\left\{\frac{\pi}{2}+\tan ^{-1}\left(\frac{x}{h}\right)\right\}
$$

Metode inversi yang digunakan untuk mendapatkan parameter model yang optimal adalah metode non liniar dengan pendekatan linear. Rumusan metoda inversi non-linier dengan pendekatan non-linier dilakukan menggunakan deret Taylor pada suku pertama dan mengabaikan suku yang lebih tinggi pada deret Taylor di sekitar $\mathrm{x}+\Delta \mathrm{x}$ sebagai berikut:

$$
\mathrm{f}_{(\mathrm{x}+\Delta \mathrm{x})}=\mathrm{f}_{(\mathrm{x})}+\mathrm{f}^{\prime}(\mathrm{x}) \Delta \mathrm{x}
$$

$f_{(x+\Delta x)}$ adalah data hasil pengukuran yang ditulis dengan $\mathbf{d}, \mathrm{f}_{(\mathrm{x})}$ adalah hasil perhitungan (respon model) yaitu $\mathbf{g}\left(\mathbf{m}_{\mathbf{0}}\right)$ dan $\mathrm{f}^{\prime}{ }_{(\mathrm{x})}$ turunan pertama parameter model yang membentuk matriks Jacobi yang ditulis $\mathbf{J} \mathbf{0}$, sehingga:

$$
\mathrm{d}=\mathrm{g}\left(\mathrm{m}_{0}\right)+\mathrm{J}_{0} \Delta \mathrm{m}_{0}
$$

dengan nilai matrik Jacobi $\mathrm{J}_{0}$ adalah turunan parsial nilai gravitasi terhadap parameter model yang dioptimasi. Dari persamaan 6 didapatkan:

$$
\mathrm{d}-\mathrm{g}\left(\mathrm{m}_{0}\right)=\mathrm{J}_{0} \Delta \mathrm{m}
$$

sehingga:

$$
\begin{aligned}
& \Delta \mathrm{m}=\operatorname{inv}\left(\mathrm{J}_{0}\right)^{*}\left(\mathrm{~d}-\mathrm{g}\left(\mathrm{m}_{0}\right)\right) \\
& \mathrm{d}-\mathrm{g}\left(\mathrm{m}_{0}\right)=\Delta \mathrm{d}
\end{aligned}
$$

Maka nilai $\Delta \mathbf{d}$ saat ini memiliki hubungan yang linear dengan $\Delta \mathbf{m}$ sehingga dapat diselesaikan dengan metode LSQR. Untuk mendapatkan nilai parameter model yang optimal dilakukan perhitungan berulang (iterasi) dengan $\mathbf{m}=\mathbf{m}_{\mathbf{0}}+\Delta \mathbf{m}$ hingga didapatkan nilai $\Delta \mathbf{d}$ minimum. Iterasi akan dihentikan saat nilai $\boldsymbol{\Delta} \mathbf{d}$ sangat kecil dengan batas tertentu. Nilai $\Delta \mathbf{d}$ yang sangat kecil menunjukkan bahwa nilai $\mathbf{m} \approx \mathbf{m}_{\mathbf{0}}$ sehingga parameter model yang dioptimasi memiliki nilai yang sangat dekat dengan nilai sesungguhnya (Grandis, 2009). 


\section{HASIL DAN PEMBAHASAN}

Ujicoba data program inversi sesar pasca gempa dilakukan dengan data seintetis yang dihasilkan oleh perhitungan forward modelling. Nilai percepatan gravitasi pada titik pengukuran untuk tiap model forward dihitung secara numeris dengan konvolusi sebagaimana persamaan (1). Hasil kali kontras densitas dengan ketebalan model atau disebut faktor amplitudo untuk tiap model dibuat bervariasi.

Tabel 1. Parameter Model untuk Mendapatkan Data Sintetis

\begin{tabular}{ccccc}
\hline Model & $\begin{array}{c}\text { Posisi } \\
(\mathrm{m})\end{array}$ & $\begin{array}{c}\text { Kedalaman } \\
(\mathrm{m})\end{array}$ & $\begin{array}{c}\text { Faktor } \\
\text { Amplitudo } \\
\left(\mathrm{kg} / \mathrm{m}^{2}\right)\end{array}$ & $\begin{array}{c}\text { Anomali } \\
\text { maksimum } \\
(\mathrm{milliGal})\end{array}$ \\
\hline 1 & 50 & 20 & 2000 & 82,9149 \\
\hline 2 & 75 & 25 & 2200 & 93,1848 \\
\hline 3 & 100 & 30 & 2400 & 98,5848 \\
\hline
\end{tabular}

Data sintetis yang dibuat didasarkan dari 3 model yang berbeda kedalaman, faktor amplitudo dan posisinya. Kedalaman pada model 1, 2 dan 3 masing-masing sebesar 20, 25 dan 30 meter. Faktor amplitudo model 1, 2 dan 3 masing-masing sebesar 2000, 2200 dan 2400 kg/m2. Posisi sesar pada model 1, 2 dan 3 adalah 50, 75 dan 100 meter. Tabel 1 menunjukkan nilainilai parameter untuk 3 model forward yang berbeda. Parameter tersebut yaitu posisi, kedalaman dan faktor amplitudo. Anomali maksimum yang sudah disisipi oleh noise pada tiap-tiap model juga ditampilkan pada tabel tersebut.

Tabel 2.Parameter Model Awal (mo) dan Hasil Inversi (mi)

\begin{tabular}{ccccccc}
\hline Model & \multicolumn{2}{c}{$\begin{array}{c}\text { Posisi } \\
(\mathrm{m})\end{array}$} & $\begin{array}{c}\text { Kedalaman } \\
(\mathrm{m})\end{array}$ & \multicolumn{2}{c}{$\begin{array}{c}\text { Faktor } \\
\text { Amplitudo } \\
\left(\mathrm{kg} / \mathrm{m}^{2}\right)\end{array}$} \\
\hline & xo & xi & ho & hi & Ao & $\mathrm{Ai}$ \\
\hline 1 & 45 & 50,3 & 18 & 20,2 & 1650 & 1512 \\
\hline 2 & 68 & 75,2 & 23 & 24,9 & 2200 & 2021 \\
\hline 3 & 90 & 99,8 & 33 & 30,1 & 2750 & 2519 \\
\hline
\end{tabular}

Data sintetis yang dihasilkan oleh forward modelling adalah data yang bebas dari noise. Data real lapangan pada kenyataanya tidak pernah terlepas dari noise. Untuk membuat data sisntetis lebih realistis, maka pada data sintetis disisipkan noise yang dibangkitkan dari nilai random dengan amplitudo tertentu agar mendekati nilai noise di lapangan.

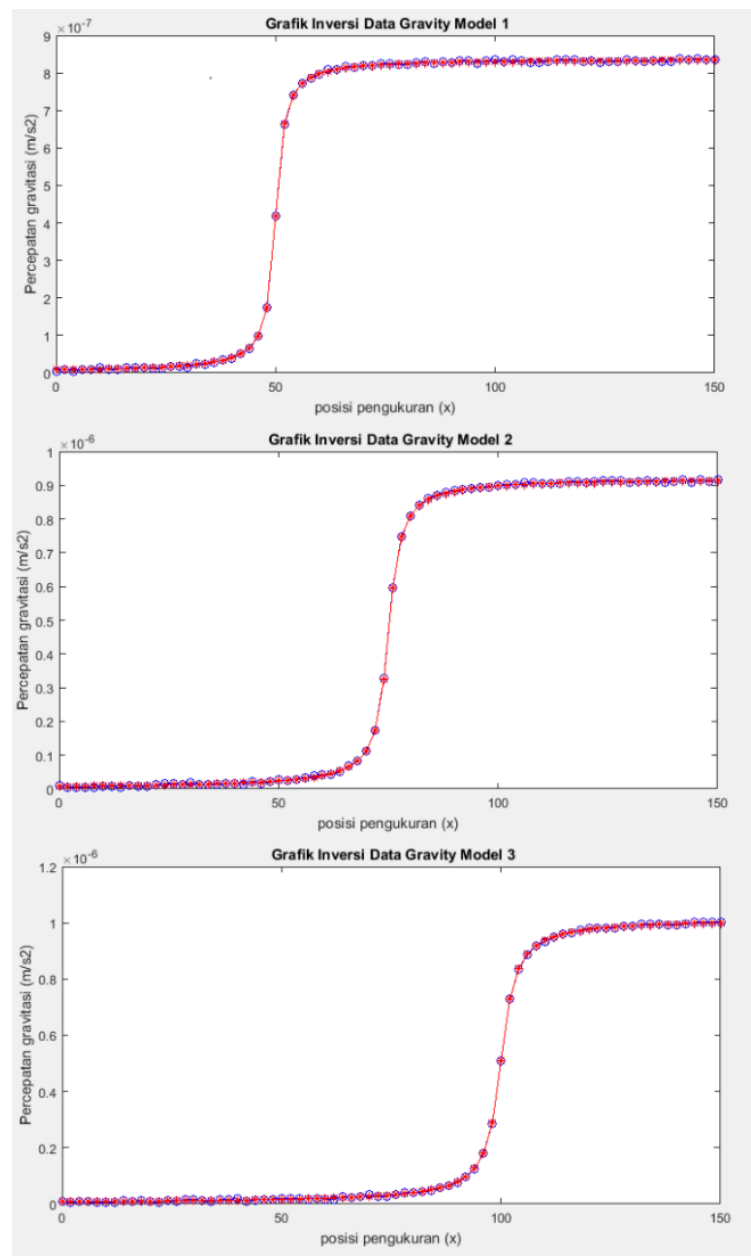

Gambar 4. Grafik hasil inversi pada 3 data sintetis dengan parameter model yang berbeda yaitu model 1, model 2 dan model 3

Gambar 4 menunjukkan grafik hasil inversi pada 3 data sintetis dengan parameter model yang berbeda-beda. Gambar bagian atas adalah hasil inversi model 1, gambar tengah adalah hasil inversi model 2, sedangkan Gambar bagian bawah adalah hasil inversi model 3. Dari ketiga grafik tersebut, tampak bahwa data gravitasi hasil inversi memiliki nilai sangat dekat dengan nilai data sintetis. Hal ini menunjukkan bahwa program inversi memiliki kestabilan yang bagus dengan nilai $R M S$ yang tergantung dari amplitudo noise semata. 
Hasil inversi pada model 1 menunjukkan bahwa untuk mendapatkan model optimal, dibutuhkan iterasi hingga 7 kali. Nilai RMS error pada model 1 sebesar 1,23. $10^{-5}$. Inversi pada model 2 terhenti pada iterasi yang ke 12 , dengan nilai $R M S$ error 5,23. $10^{-5}$. Optimasi model ke 3 didapatkan pada iterasi yang ke 8 dengan nilai $R M S$ sebesar 3,96. $10^{-5}$. Tabel 2 menunjukkan nilai-nilai parameter untuk 3 model awal dan hasil inversi dari 3 model forward yang berbeda. Parameter tersebut yaitu posisi, kedalaman dan faktor amplitudo.

Tabel 3. Parameter Inversi Berupa Jumlah Iterasi dan RMS error

\begin{tabular}{ccc}
\hline Model & Iterasi & RMS error \\
\hline 1 & 7 & $1,23 \cdot 10^{-5}$ \\
\hline 2 & 12 & $5,23 \cdot 10^{-5}$ \\
\hline 3 & 8 & $3,96.10^{-5}$ \\
\hline
\end{tabular}

Dari tabel 3 terlihat bahwa iterasi terpendek dihasilkan dari data sintetis pada model 1 yaitu iterasi ke 7 , sedangkan iterasi terpanjang dihasilkan oleh model 2 pada iterasi ke 12. RMS error terbesar ada pada model 2 yaitu sebesar $5,23.10^{-5}$ sedangkan terkecil ada pada model 1 dengan yaitu sebesar $1,23 \cdot 10^{-5}$.

\section{PENUTUP}

Program Inversi yang telah dibuat mampu memberikan hasil inversi yang nilainya sesuai dengan model forward. Terdapat perbedaan yang cukup kecil antara model hasil inversi dengan model forward. Hal ini disebabkan oleh penambahan noise pada data sintetis.

Semakin kecil nilai $R M S$ error yang disyaratkan, maka jumlah iterasinya untuk mendapatkan nilai optimal semakin banyak. Nilai syarat $R M S$ yang terlalu kecil akan mengakibatkan nilai tersebut tak terpenuhi, sehingga iterasi berjalan terus menerus tanpa henti. Untuk menghindari masalah ini nilai $R M S$ harus ditentukan dengan tepat.

\section{REFERENSI}

Dafis, K., Li, Y., \& Batzle, M. 2008. Timelapse gravity monitoring: A systematic 4D approach with application to aquifer storage and recovery. GEOPHYSICS, 73(6), 6169.

Eiken, O., Zumberge, M., \& Stenvold, T., .2004. Gravimetric monitoring of gas production from the Troll field. SEG Int'l Exposition and 74th Annual Meeting, Denver, Colorado

Gettings, P., Harris, R.N., Allis, R.G., \& Chapman, D.S. 2002. Gravity Signals at the Geysers Geothermal System. Proceedings, Twenty-Seventh Workshop on Geothermal Reservoir Engineering, Stanford University.

Grandis, H. 2009. Pengantar pemodelan Inversi Geofisika. Institute Teknologi Bandung. Himpunan Ahli Geofisika Indonesia. Bandung. p105-113,

Kadir, W. G. A. 1999. Survey Gravitasi 4D dan dinamika Sumber Bawah Permukaan. Proceeding Himpunan Ahli Geofisika Indonesia. 94-99.

Telford, W. M., Telford, W. M., Geldart, L. P., Sheriff, R. E., \& Sheriff, R. E. 1990. Applied geophysics (Vol. 1). Cambridge university press.

Zuhdi, M., Sismanto, Setiawan, A., Setyowiyoto, J., Susilo, A., \& Sarkowi, M. 2018. Radial Derivative and Radial Inversion for Interpreting 4D Gravity Anomaly Due to Fluids Injection Around Reservoir, TELKOMNIKA, 16(6), 2855 2863. 